\title{
Expression in Systemic Lupus Erythematosus of an Idiotype Common to DNA-binding and Nonbinding Monoclonal Antibodies Produced by Normal Human Lymphoid Cells
}

Ewa Cairns, Helene Massicotte, and David A. Bell

Departments of Medicine and Microbiology and Immunology, University of Western Ontario, University Hospital, Rheumatic Diseases Unit, London, Ontario, Canada, N6A 5 A5

\begin{abstract}
Rabbit antiserum raised against a normal-derived monoclonal anti-DNA antibody KIM 4.6.3 (IgM lambda) was used for idiotype analyses. This anti-serum (anti-4.6.3 ID) was rendered specific for KIM 4.6.3 idiotype (4.6.3 ID) by absorption with normal human IgM and IgG. The specificity of anti-4.6.3 was shown by its ability to bind to KIM 4.6.3 antibody but not to normal human IgM and IgG, by inhibition of anti-4.6.3 ID reactivity with KIM 4.6.3 antibody by the homologous monoclonal antibody and by the ability of anti-4.6.3 ID to inhibit the binding of single stranded DNA with KIM 4.6.3 antibody. The 4.6.3 ID was found to be commonly expressed since it was detected among 33\% (10/30) DNA and 32\% (23/72) nonDNA-reactive monoclonal antibodies that were obtained from five different unrelated normal individuals. The binding to SSDNA of the majority of idiotype positive anti-DNA antibodies however was not blocked by anti-4.6.3 ID suggesting that among these other monoclonal antibodies its expression is outside of the antigen binding site. The 4.6.3 ID, which was present among some normal-derived monoclonal IgM molecules was also found at a high frequency $(90 \%)$ in the sera of patients with systemic lupus erythematosus (SLE) but only at a low frequency (24\%) and concentration in normal sera. The level of 4.6.3 ID in SLE did not correlate with serum IgM and IgG nor with anti-DNA antibody concentrations. Idiotypic relatedness between SLE serum antibodies and monoclonal antiDNA antibodies of normals implies the existence of a crossreactive idiotype family and implies that a conserved common gene or closely related genes exist in the germ line encoding these 4.6.3 ID positive antibodies some of which are not exclusively associated with nucleic acid reactivity. The expression of these germ line genes in vivo thus distinguishes SLE from normals.
\end{abstract}

\section{Introduction}

Anti-DNA autoantibodies are characteristic of human systemic lupus erythematosus (SLE) and its murine equivalent. Genes encoding anti-DNA antibodies, however, are not re-

Address reprint requests to Dr. Bell, Department of Medicine, University Hospital, Box 5339, Station A, London, Ontario N6A 5A5, Canada.

Received for publication 13 May 1988 and in revised form 24 October 1988.

\footnotetext{
J. Clin. Invest.

(c) The American Society for Clinical Investigation, Inc.

0021-9738/89/03/1002/08 \$2.00
}

Volume 83, March 1989, 1002-1009 stricted to this autoimmune disease and are part of the normal $B$ cell repertoire. The generation of anti-DNA antibody responses was demonstrated in cultures of peripheral blood lymphocytes $(1,2)$, normal tonsillar lymphocytes $(1)$, in a human:human hybridoma system derived from lymphoid cells of normal individuals (3-5) and in nonautoimmune strains of mice $(6,7)$. These normal-derived anti-DNA antibodies are qualitatively identical to those produced in SLE in that they exhibit an identical spectrum of antigen binding characteristics in which not only nucleic acid antigens are included but also human IgG, cardiolipin, and vimentin (1, 8-10).

The anti-DNA antibodies of SLE express cross-reactive idiotypes as determined using monoclonal and polyclonal antiidiotypic reagents (11-13). SLE anti-DNA antibody idiotypes were detected in the sera of normal strains of mice (14), in culture supernatants of splenic cells obtained from normal mice (15), in sera from healthy members of SLE families (16), and on myeloma immunoglobulin recognizing bacterial antigen (17). These findings indicate a common derivative in SLE and normals of DNA and non-DNA-reactive antibodies from a single or a limited number of related genes. In the murine system, the usage of common genetic elements for MRL/lpr/ lpr anti-DNA antibody and for antibodies to exogenous antigens has been recently demonstrated by nucleotide sequence data comparison (18).

In this paper we provide additional evidence for the possible recruitment in SLE and normals of the same or closely related genes in DNA and non-DNA antibody responses in which major cross-reactive idiotype of normal-derived monoclonal anti-DNA antibody frequently occurs.

\section{Methods}

Characteristics of monoclonal anti-DNA antibody 4.6.3. KIM 4.6.3 monoclonal anti-DNA antibody was derived from a hybridoma obtained after the fusion of tonsillar lymphoid cells from a normal individual with the lymphoblastoid cell line GM 4672 (Human Genetic Mutant Cell Repository, Camden, NJ) as previously described (3). KIM 4.6.3 monoclonal anti-DNA antibody was of IgM $\lambda$ isotype and it displayed reactivity with various nucleic acid antigens including: single stranded DNA (ssDNA), ${ }^{1}$ native DNA (DNA), synthetic double stranded polymers: polydeoxyguanylate-polydeoxycytidylate (poly dG $\cdot$ poly $\mathrm{dC}$ ) and polydeoxyadenylate-thymidylate sodium salt (poly [dA-dT]), a low molecular weight DNA ( 150 base pairs, $80 \%$

1. Abbreviations used in this paper: CFA, complete Freund's adjuvant; ID, idiotype; IFA, incomplete Freund's adjuvant; poly (dA-dT), polydeoxyadenylate-thymidylate sodium salt; poly $\mathrm{dG} \cdot$ poly $\mathrm{dC}$, polydeoxyguanylate-polydeoxycytidylate; NRS, normal rabbit serum; RT, room temperature; ssDNA, single-stranded DNA; S/N, supernatant; WB, washing buffer. 
double stranded [19]), and ribonucleic acid (RNA). This KIM 4.6.3 antibody bound weakly to cardiolipin.

Purification of KIM 4.6.3 anti-DNA antibody. KIM 4.6.3 antiDNA antibody was chromatographically purified on silica (Boehringer Mannheim GmbH, Mannheim, W. Germany) coupled rabbit antihuman IgM ( $\mu$ chain specific) (DAKO, Copenhagen, Denmark). The coupling of rabbit anti-human IgM to silica was performed according to the instructions from Boehringer Mannheim attached with the silica reagent. Approximately $300 \mathrm{ml}$ of the KIM 4.6 .3 hybridoma supernatant was passed at room temperature (RT) through the silica-rabbit anti-human IgM packed column (15 cm height $1 \mathrm{~cm}$ diameter). The column was then extensively washed with $3 \% \mathrm{NaCl}$ until absorbance at $280 \mathrm{~nm}$ was $<0.005$ OD units. The bound antibody was eluted with 2 $\mathrm{mol} /$ liter sodium thiocyanate (J. T. Baker Chemical Co., Phillipsburg, $\mathrm{NJ})$. 1-ml fractions were collected and those which contained protein (determined spectrophotometrically at $280 \mathrm{~nm}$ ) were pooled. The eluted antibody solution (20-25 ml) was dialyzed for $48-72 \mathrm{~h}$ at $4^{\circ} \mathrm{C}$ against six changes of PBS, pH 7.4 (Gibco Laboratories, Grand Island, NY). This dialyzed antibody solution was subsequently concentrated by Amicon Filtration on an XM 300 membrane (Amicon Corp., Lexington, MA) and underwent further final dialysis at $4^{\circ} \mathrm{C}$ with three changes of PBS pH 7.4 (Gibco Laboratories) during $48 \mathrm{~h}$. This preparation yielded $5 \mathrm{ml}$ of $\mathrm{IgM}$ antibody solution $(120 \mu \mathrm{g} / \mathrm{ml})$, which had reactivity with ssDNA and which lacked detectable human IgG or rabbit Ig when tested by ELISA (3).

Production of anti-4.6.3 idiotype (anti-4.6.3 ID). The anti-4.6.3 ID was prepared in 6-8 wk old female New Zealand rabbits. The test rabbits were injected with $100 \mu \mathrm{g} / \mathrm{rabbit}$ of purified KIM 4.6.3 antibody in complete Freund's adjuvant (CFA) (Difco Laboratories, Detroit, $\mathrm{MI}$ ) and the control rabbits received saline (equivalent volume to KIM 4.6.3 antibody solution) in CFA. These injections were done intradermally into three different places in the neck region. 3 and 5 wk later test and control rabbits were immunized again with $50 \mu \mathrm{g}$ of KIM 4.6.3 antibody/rabbit in incomplete Freund's adjuvant (IFA) (Difco Laboratories) and saline in IFA, respectively. These injections were given intramuscularly in the thigh region. $2 \mathrm{wk}$ after the last immunization rabbits were bled through the ear and the control serum (normal rabbit serum, NRS) and the test serum (anti-4.6.3 serum) were collected.

The anti-4.6.3 serum as well as NRS were extensively absorbed on normal human IgM (Cappel Laboratories, Cochranville, PA) coupled silica (Boehringer Mannheim $\mathrm{GmbH}$ ) and on normal human IgG coupled agarose (Sigma Chemical Co., St. Louis, MO) to remove antibodies to the constant region of human immunoglobulin light and heavy chains from the anti-4.6.3 serum. All absorptions ( 2 on IgG and 4 on IgM) were carried out at RT in $15 \mathrm{ml}$ screw cap tubes (Corning Glass Works, Corning, NY) containing $2 \mathrm{ml}$ of packed absorbant and 3 $\mathrm{ml}$ of serum diluted 1:1 with PBS, pH 7.4 (Gibco Laboratories). Sera were incubated with each absorbant for $2 \mathrm{~h}$ and tubes were in a constant rocking motion $\left(45^{\circ} \mathrm{C}, 6\right.$ cycles $\left./ \mathrm{min}\right)$ during that time. Sera were removed from the tubes after centrifugation at $400 \mathrm{~g}$ for $10 \mathrm{~min}$. Anti-4.6.3 serum which had no reactivity in ELISA with normal human IgG and IgM (both from Cappel), but bound to 4.6 .3 antibody was used and was considered as anti-4.6.3 idiotype (anti-4.6.3 ID).

ELISA for binding of rabbit sera to IgM, IgG, or to KIM 4.6.3 antibody. $50 \mu \mathrm{l}$ of normal human IgM or normal human IgG (both from Cappel) or purified KIM 4.6.3 antibody each at $5 \mu \mathrm{g} / \mathrm{ml}$ in carbonate-bicarbonate buffer $\mathrm{pH} 9.6$ were coated onto the polystyrene round bottom wells of Cooke Microtiter plates (Dynatech Laboratories Inc., Dynatech Corp., Alexandria, VA). Wells coated with buffer only served as controls. The plates were incubated after coating at $4^{\circ} \mathrm{C}$ overnight and then washed three times with the washing buffer (WB) $0.1 \mathrm{M}$ Tris-HCl, pH 7.4 containing $0.1 \%$ BSA (Boehringer Mannheim $\mathrm{GmbH}$ ) and $0.05 \%$ tween 20 (Sigma Chemical Co.). Subsequently all the wells were totally filled with $2 \% \mathrm{BSA}$ in $0.1 \mathrm{M}$ Tris- $\mathrm{HCl} \mathrm{pH} 7.4$ and incubated for $2 \mathrm{~h}$ at RT. After one wash with WB $50 \mu \mathrm{l}$ of unabsorbed anti-4.6.3 serum or anti-4.6.3 ID or unabsorbed NRS or absorbed NRS diluted $\left(1: 50-1: 10^{5}\right)$ in $0.1 \%$ BSA $0.1 \mathrm{M}$ Tris- $\mathrm{HCl}$, pH 7.4 were pipet- ted into the antigen-coated and control wells. The plates were left overnight at $4^{\circ} \mathrm{C}$. The following morning they were washed five times with WB and $50 \mu$ l of $1: 1000$ dilution in 0.1\% BSA-PBS pH 7.4 of alkaline phosphatase conjugated sheep $\mathrm{F}(\mathrm{ab})_{2}$ anti-rabbit IgG (Sigma Chemical Co.) was added to the wells. After overnight incubation at $4^{\circ} \mathrm{C}$ the plates were washed again five times with WB and the wells were filled with $50 \mu$ l of para-nitrophenyl phosphate (Sigma Chemical Co.) at $1 \mathrm{mg} / \mathrm{ml}$ in diethanolamine buffer, $\mathrm{pH} 9.8$. The enzymatic reaction was developed for $30 \mathrm{~min}$ at $37^{\circ} \mathrm{C}$ and then stopped with 25 $\mu \mathrm{l} /$ well of $3 \mathrm{M} \mathrm{NaOH}$. Optical densities were read in a Titertek Multiskan (Dynatech Laboratories, Inc.) at $405 \mathrm{~nm}$.

Inhibition of KIM 4.6.3 AB binding to ssDNA by anti-4.6.3 ID. KIM 4.6.3 IgM purified anti-DNA antibody $(6 \mu \mathrm{g} / \mathrm{ml})$ diluted in $0.1 \mathrm{M}$ Tris- $\mathrm{HCl}$ pH 7.4 was mixed with an equal volume of anti-4.6.3 ID or NRS diluted in $0.1 \%$ BSA $0.1 \mathrm{M}$ Tris- $\mathrm{HCl}$ pH 7.4 from a starting protein concentration of $5 \mathrm{mg} / \mathrm{ml}$. The mixture was incubated for $2 \mathrm{~h}$ at $37^{\circ} \mathrm{C}$ before using it in ELISA for binding to ssDNA as previously described (3). The percent inhibition was calculated by comparing the inhibition of KIM 4.6.3 to DNA by anti-4.6.3 or NRS with the inhibition of KIM 4.6.3 to DNA by buffer diluent $(0.1 \%$ BSA in $0.1 \mathrm{M}$ Tris-HCl, $\mathrm{pH}$ 7.4).

Inhibition of anti-4.6.3 ID binding to KIM 4.6.3 ID. $200 \mu \mathrm{l}$ of absorbed anti-4.6.3 ID or NRS (both at protein concentrations of 5 $\mu \mathrm{g} / \mathrm{ml}$ ) were mixed either with an equal volume of: affinity purified KIM 4.6.3 AB, different hybridoma $\mathrm{S} / \mathrm{N}$, normal human IgM or IgG. The final amount of IgM or IgG competitors varied between 0.24 and $0.007 \mu \mathrm{g}$. In addition, undiluted hybridoma fusion partner GM4672 $\mathrm{S} / \mathrm{N}$ and diluent control consisting of $0.1 \% \mathrm{BSA} 0.1 \mathrm{M}$ Tris- $\mathrm{HCl} \mathrm{pH} 7.4$ were also tested as inhibitors.

The mixtures were incubated for $2 \mathrm{~h}$ at $37^{\circ} \mathrm{C}$ before testing in ELISA. This ELISA procedure for binding of anti-4.6.3 ID to KIM 4.6.3 antibody coated on the wells using sheep $F(a b)_{2}$ fragment of IgG conjugated with alkaline phosphatase was described above. The percent inhibition was expressed according to the formula: \% inhibition $=100 \%-\left[\left(\mathrm{OD}_{405}\right.\right.$ anti-4.6.3 ID with inhibitor $/ \mathrm{OD}_{405}$ anti-4.6.3 ID with buffer) $\times 100 \%$ ].

ELISA for binding of anti-4.6.3 ID to the monoclonal DNA or non-DNA antibodies or to the normal or SLE sera. $50 \mu \mathrm{l}$ of undiluted hybridoma $\mathrm{S} / \mathrm{N}$ containing DNA or non-DNA binding monoclonal antibodies or hybridoma growth medium (HGM) or GM 4672 lymphoblastoid cell line $\mathrm{S} / \mathrm{N}$, or normal or SLE sera or the dialyzed $50 \%$ ammonium sulfate fraction of the sera, which were diluted at $1: 10^{2}$, $1: 10^{3}, 1: 10^{4}, 1: 10^{5}$ in carbonate-bicarbonate buffer $\mathrm{pH} 9.6$ were coated overnight at $4^{\circ} \mathrm{C}$ onto the polystyrene wells of Cooke Microtiter plates (Dynatech Laboratories Inc.). The plates were then washed three times with WB and incubated for $2 \mathrm{~h}$ at RT with $2 \%$ BSA in $0.1 \mathrm{M}$ Tris- $\mathrm{HCl}$ $\mathrm{pH}$ 7.4. After one wash with WB $50 \mu \mathrm{l}$ of anti-4.6.3 ID or NRS diluted 1:500 in $0.1 \mathrm{M}$ Tris- $\mathrm{HCl}$ pH 7.4 containing $0.1 \%$ BSA was pipetted into the wells and left overnight at $4^{\circ} \mathrm{C}$. The plates were subsequently washed five times with $0.1 \%$ BSA in $0.1 \mathrm{M}$ Tris- $\mathrm{HCl} \mathrm{pH} 7.4$ and $50 \mu \mathrm{l}$ of alkaline phosphatase conjugated sheep $\mathrm{F}(\mathrm{ab})_{2}$ anti-rabbit IgG diluted $1: 1,000$ in $0.1 \%$ BSA-PBS pH 7.4 was added to the wells. These plates were left overnight at $4^{\circ} \mathrm{C}$ and were subsequently washed five times with $0.1 \% \mathrm{BSA}-0.1 \mathrm{M}$ Tris- $\mathrm{HCl} \mathrm{pH}$ 7.4. The enzymatic reaction was developed with $p$-nitrophenyl phosphate $(1 \mathrm{mg} / \mathrm{ml})$ in diethanolamine buffer $\mathrm{pH} 9.8$ for $1 \mathrm{~h}$ at $37^{\circ} \mathrm{C}$.

\section{Results}

Characteristics of monoclonal anti-DNA antibody KIM 4.6.3. Human monoclonal IgM anti-DNA antibody KIM 4.6.3 was derived from a hybridoma obtained from the fusion between the lymphoblastoid cell line GM 4672 and the tonsillar lymphoid cells of a normal individual. KIM 4.6.3 anti-DNA antibody was the product of a stable clone continuously maintained in culture over a year. This antibody exhibited a broad spectrum of reactivity as indicated by its binding to a variety of 
nucleic acid antigens (ssDNA, DNA, poly(dA-dT), poly dG - poly dC, low molecular weight 150 bp DNA) and also to cardiolipin. The reactivity of KIM 4.6.3 antibody with these antigens was retained in different culture samples and after its purification on a rabbit anti-human IgM affinity column as determined by ELISA (data not shown).

The polyspecific nature of KIM 4.6.3 antibody was also observed with $55 \%$ of the other monoclonal anti-DNA antibodies produced by different clones obtained in the same fusion. For this reason KIM 4.6.3 antibody was considered a prototype for polyspecific anti-DNA antibody and was chosen for antiidiotypic antibody production.

Specificity of anti-4.6.3 idiotype for KIM 4.6.3 idiotype. Immunizations of a rabbit with adjuvant-emulsified affinitypurified human monoclonal KIM 4.6.3 anti-DNA antibody resulted in the production of an antiserum that, following absorptions with normal (non-DNA reactive) human IgM and IgG, was rendered specific for KIM 4.6.3 ID. This specificity is documented in Fig. 1 which shows that in direct ELISA the absorbed anti-4.6.3 serum reacts with KIM 4.6.3 antibody in a dose-dependent fashion but does not bind to normal human IgG and IgM. In contrast, the control serum (NRS) obtained from an adjuvant immunized rabbit and absorbed in an identical manner as anti-4.6.3 exhibited no binding to any of the three antigens tested (Fig. 1). This indicates not only the restricted recognition of prepared anti-4.6.3 serum for the variable portion of KIM 4.6.3 antibody but also that this recognition was not induced by adjuvant injection.

The specificity of anti-4.6.3 ID for the variable portion of 4.6.3 anti-DNA antibody was subsequently explored in inhibition studies. As shown in Fig. 2 the anti-4.6.3 ID inhibited KIM 4.6.3 antibody reactivity with ssDNA antigen. This inhibition was dependent on the dose of the anti-4.6.3 ID. At $1 / 100$ dilution of anti-4.6.3 ID there was $100 \%$ inhibition of the 4.6.3 antibody binding to ssDNA as compared to the binding of 4.6.3 antibody to ssDNA in the presence of $0.1 \%$ BSA $0.1 \mathrm{M}$ Tris- $\mathrm{HCl} \mathrm{pH} 7.4$ buffer control. The same dilution and serum protein concentration $(5 \mu \mathrm{g} / \mathrm{ml})$ of NRS did not interfere with KIM 4.6.3 antibody binding to the nucleic acid antigen. These results indicate that the rabbit anti-4.6.3 ID recognized an epitope on the variable portion of KIM 4.6.3 antibody that is at, or close to, the antigen binding site.

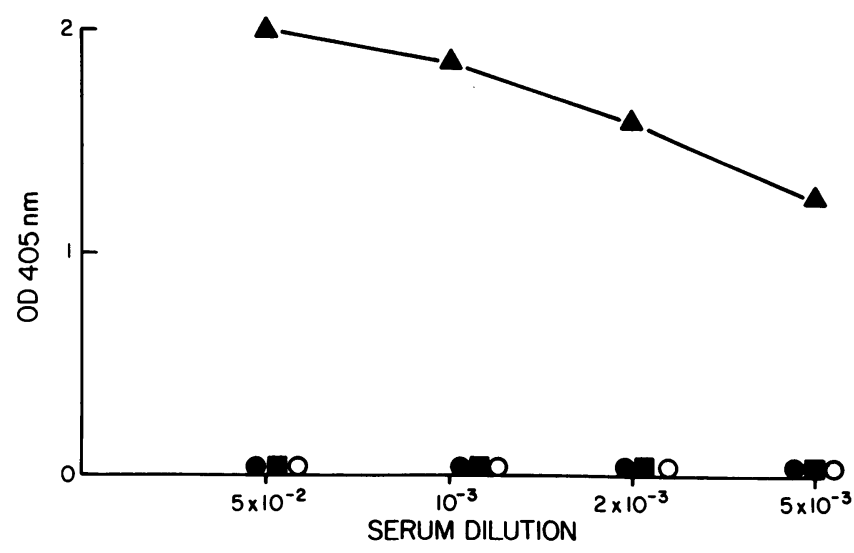

Figure 1. Binding of absorbed anti-4.6.3 serum to KIM 4.6.3 anti-

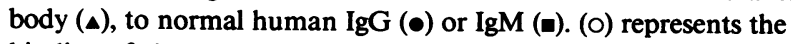
binding of absorbed NRS to all of these antigens.

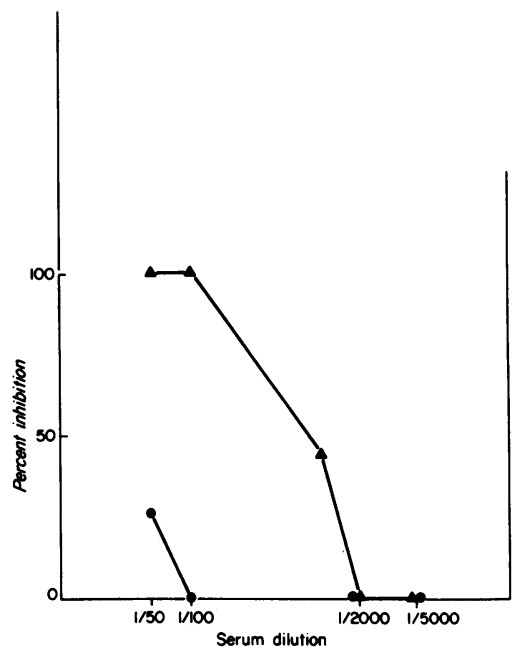

Figure 2. Inhibition of KIM 4.6.3 antibody (6 $\mu \mathrm{g} / \mathrm{ml})$ binding to ssDNA $(10 \mu \mathrm{g} / \mathrm{ml}$ coated on the well) by anti-4.6.3 serum or NRS. (Inhibitor: anti-4.6.3 (ـ) serum; NRS (--).)

In a different inhibition assay (Fig. 3), the binding of anti-4.6.3 ID to KIM 4.6.3 antibody was abolished or decreased in the presence of affinity purified homologous antibody. The homologous hybridoma supernatant used at an IgM concentration equivalent to the purified KIM 4.6.3 antibody showed a similar inhibitory effect. This suggests that during purification, the variable portion of KIM 4.6.3 antibody was not altered. The inhibition of anti-4.6.3 ID binding to KIM 4.6.3 AB was also observed with three of eight anti-DNA hybridoma S/N tested: KIM $4.5(\operatorname{IgM} \lambda)$, KIM $4.3(\operatorname{IgM} \lambda)$ and KIM 9.1 (IgM $\kappa)$ (Fig. 3) but not with KIM 11.4 (IgM $\lambda$ ) (Fig. 3), KIM 7.5 (IgM, light chain not determined), KIM $11.2(\operatorname{IgM} \kappa)$, KIM $12.2(\operatorname{IgM} \kappa)$ and $\mathrm{KIM} 12.5(\operatorname{IgM} \kappa)$ (results not shown).

KIM 9.1 produced about $60 \%$ less inhibition than KIM 4.6.3, KIM 4.5 and KIM 4.3 S/N. Non-DNA binding antibodies from hybridoma supernatants KIM 13.1 (IgM $\kappa$, anticardiolipin antibody) and KIM V (IgM, light chain and antigen specificity not determined) (Fig. 3) as well as normal human IgM, IgG, or IgG $x$ containing S/N from GM 4672 cell line (used undiluted) had no inhibitory effect.

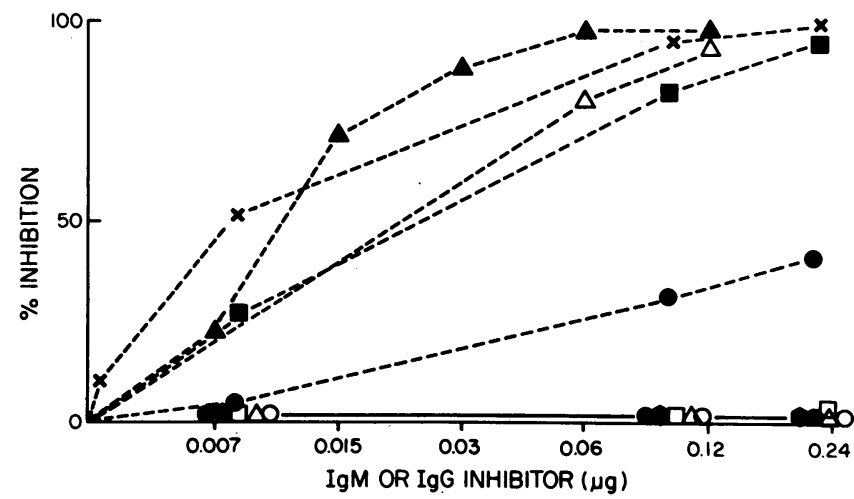

Figure 3. Inhibition of anti-4.6.3 serum binding to KIM 4.6.3 affinity purified antibody by DNA and non-DNA binding antibodies. DNA binding inhibitors: KIM 4.6.3 purified antibody (- - -); KIM 4.6.3 hybridoma S/N antibody (-- $\Delta--$ ); KIM 4.5 hybridoma $S / N$ antibody (-n-); KIM 4.3 hybridoma S/N antibody (-x-); KIM 9.1 hybridoma S/N antibody (-๑-); KIM 11.4 hybridoma S/N antibody $(\rightarrow-)$; Non-DNA binding inhibitors: normal human IgM (-o); normal human IgG ( $૪)$; KIM 13.1 anticardiolipin antibody hybridoma $S / N$ $(\bullet)$; KIM V hybridoma S/N antibody (- - -). 
The above results imply that anti-4.6.3 ID recognizes a public or cross-reactive idiotype which in addition to KIM 4.6.3 is expressed by some other monoclonal anti-DNA antibodies (KIM 4.5, KIM 4.3, KIM 9.1).

Reactivity of anti-4.6.3 ID with DNA and non-DNA binding monoclonal antibodies. The qualitative assessment of 4.6.3 expression was performed by directly testing a large panel (102) of undiluted hybridoma supernatants for binding to anti-4.6.3 ID in direct ELISA. 30 of these supernatants contained IgM anti-DNA and/or anticardiolipin binding antibodies, while the remaining 72 supernatants contained IgM antibodies without DNA and/or cardiolipin reactivity. These tested antibodies were derived from the fusions of four different unrelated normal individuals (KIM) (Fig. 4), KIR, KEL, CAR, and ROB (Table I). In supernatants from KIM hybridomas, 4.6.3 ID was detected in 7/22 (32\%) anti-DNA and/or anticardiolipin antibodies in addition to KIM 4.6.3 S/N and KIM 4.6.3 affinity purified antibody (KIM P 4.6.3) (Fig. $4 a$ ). In KIM hybridoma supernatants lacking reactivity with nucleic acid and/or cardiolipin, 7/22 (32\%) IgM antibodies were 4.6.3 ID positive (Fig. 4 b).

The inability to detect 4.6.3 ID did not appear to be a function of low IgM expression in 4.6.3 ID negative supernatants since some of them showed equal or higher IgM concentrations (e.g., KIM 7.2, $8 \mu \mathrm{g} / \mathrm{ml} \mathrm{IgM;} \mathrm{KIM} \mathrm{11.4,} 2.1 \mu \mathrm{g} / \mathrm{ml}$ IgM) than the 4.6.3 ID positive supernatants, (e.g., KIM 4.3, $0.77 \mu \mathrm{g} / \mathrm{ml}$ IgM; KIM 10.2, $0.512 \mu \mathrm{g} / \mathrm{ml}$ IgM; KIM 9.2, 0.74 $\mu \mathrm{g} / \mathrm{ml}$ IgM; KIM $4.5,0.45 \mu \mathrm{g} / \mathrm{ml}$ IgM). The concentration of IgM in affinity purified KIM P 4.6.3 preparation was $6 \mu \mathrm{g} / \mathrm{ml}$.

The expression of 4.6.3 ID positive KIM IgM anti-DNA antibodies does not appear to be solely a function of the light chain since both lambda (KIM: 4.3, 4.5, 5.1, 10.2) and kappa (KIM: 9.1, 9.2) light chains were expressed by these antibodies even though the original KIM 4.6.3 used for anti-ID production was of IgM lambda type. Thus, the preference for IgM

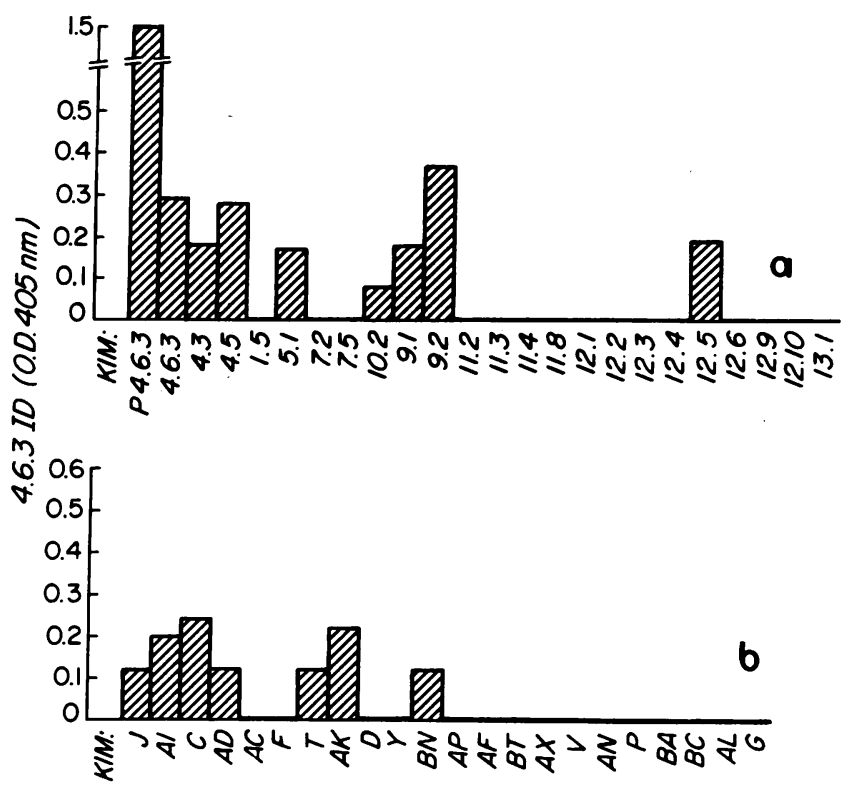

Figure 4. The expression of 4.6.3 ID on monoclonal DNA binding $(a)$ and non-DNA binding $(b)$ antibodies obtained in the same fusion. (P 4.6.3 refers to the purified 4.6.3 antibody; other numbers and letters refer to hybridoma $\mathrm{S} / \mathrm{N}$.)
Table I. Expression of 4.6.3 ID in Different Tonsil Hybridoma Supernatants Obtained in Fusions from Unrelated Normal Individuals

\begin{tabular}{lccc}
\hline $\begin{array}{c}\text { Source of tonsil } \\
\text { hybridoma S/N }\end{array}$ & $\begin{array}{c}\text { Anti-DNA } \\
\text { positive }\end{array}$ & $\begin{array}{c}\text { Anti-DNA } \\
\text { negative }\end{array}$ & $\begin{array}{c}\text { ID 4.6.3 } \\
\text { positive }\end{array}$ \\
\hline & & & $\%$ \\
KIR & 1 & - & 0 \\
KEL (N) & - & 17 & $4(23)$ \\
CAR (N) & 6 & 10 & $5(50)$ \\
& - & - & $2(33)$ \\
ROB (N) & - & 16 & $5(31)$ \\
\hline
\end{tabular}

lambda is obvious, but the explanation for inhibition by KIM 9.1 and 9.2 an IgM kappa monoclonal, has not been determined.

The majority of 4.6.3 ID positive KIM anti-DNA antibodies with the exception of KIM 4.6.3, KIM 4.3, KIM 4.5 reacted with ssDNA antigen equally well in the presence or absence of anti-4.6.3 ID competitor (results not shown). This together with the high frequency of 4.6.3 ID expression in DNA negative hybridoma supernatants suggests that the polyclonal anti-4.6.3 ID recognizes a framework rather than an antigen binding site on the majority of 4.6.3 ID positive antibodies.

The 4.6.3 ID was expressed also on hybridoma antibodies obtained from the fusions of different unrelated normal individuals $\mathrm{KIR}, \mathrm{CAR}$, and $\mathrm{ROB}$ at a frequency similar to the frequency among KIM hybridoma antibodies (23-31\%). A higher frequency $(50 \%)$ of 4.6 .3 ID expression was also detected in hybridoma supernatant from the KEL fusion (Table I). In these hybridoma supernatants 4.6.3 ID expression was also not restricted to antibodies with nucleic acid reactivities. Thus in all fusions, the overall frequency of expression of 4.6.3 ID was 33\% among DNA binding and 32\% among non-DNA binding monoclonal antibodies.

The expression of 4.6.3 ID in SLE and normal human sera. Human sera from 50 randomly chosen normal individuals and from 40 SLE patients were tested at different dilutions $\left(10^{-2}-2 \times 10^{-4}\right)$ for the presence of 4.6 .3 ID by the ELISA method using anti-4.6.3 ID.

The 4.6.3 ID was expressed in 43-90\% of the SLE and in $0-24 \%$ of normal sera depending on the dilution of serum tested (Fig. 5). Similar results were obtained with the 50\% ammonium sulfate fraction of SLE or normal serum tested in the same manner (data not shown). The idiotype was detected over a wide range of serum dilutions in SLE, from $10^{-2}$ to 2 $\times 10^{-4}$. The mean level of this ID was $0.26 \pm 0.2$ in SLE and $0.05 \pm 0.04$ in normals at a serum dilution of $10^{-3}$. At this dilution the highest mean of 4.6.3 ID binding levels appeared to approach a plateau value at $\sim 5 \times 10^{-3}$ dilution (results not presented). At serum dilutions of less than $10^{-3}$, there was a reduced 4.6.3 ID binding. Whether this represents packing, steric, charge, or other phenomena restricting 4.6.3 ID binding at very high concentrations was not determined.

The high levels and frequent expression of 4.6.3 ID in SLE were not merely a reflection of high serum immunoglobulin concentrations in these patients. This is indicated in Fig. 6 which shows a lack of correlation (correlation coefficient $r$ $=0.254$ ) between serum IgM and IgG with 4.6.3 ID. Here the 


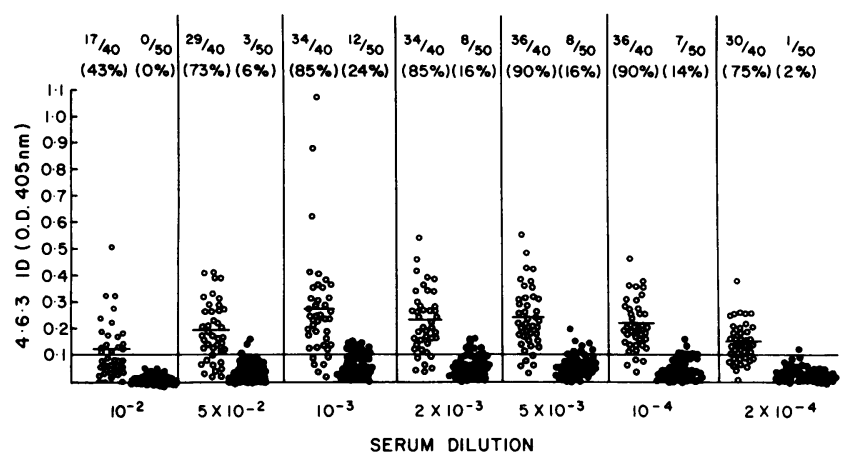

Figure 5. Presence of 4.6.3 ID in SLE and normal human sera. ((O) SLE; (•) normal sera).

relative amount of 4.6.3 ID bound to the serum-saturated wells for each individual tested is compared to the corresponding serum concentration of IgG + IgM for each of these individuals. Furthermore, only $3 / 15(20 \%)$ sera tested from patients with unexplained polyclonal hypergammaglobulinemia expressed 4.6.3 ID (data not shown). There was also no correlation found between 4.6.3 ID and the total serum IgM and IgG anti-ssDNA antibodies (Fig. 7) or anti-DNA antibodies (Fig. 8) in sera of these SLE patients.

\section{Discussion}

We have shown in this study that the 4.6.3 idiotype expressed on a normal-derived monoclonal anti-DNA antibody (KIM

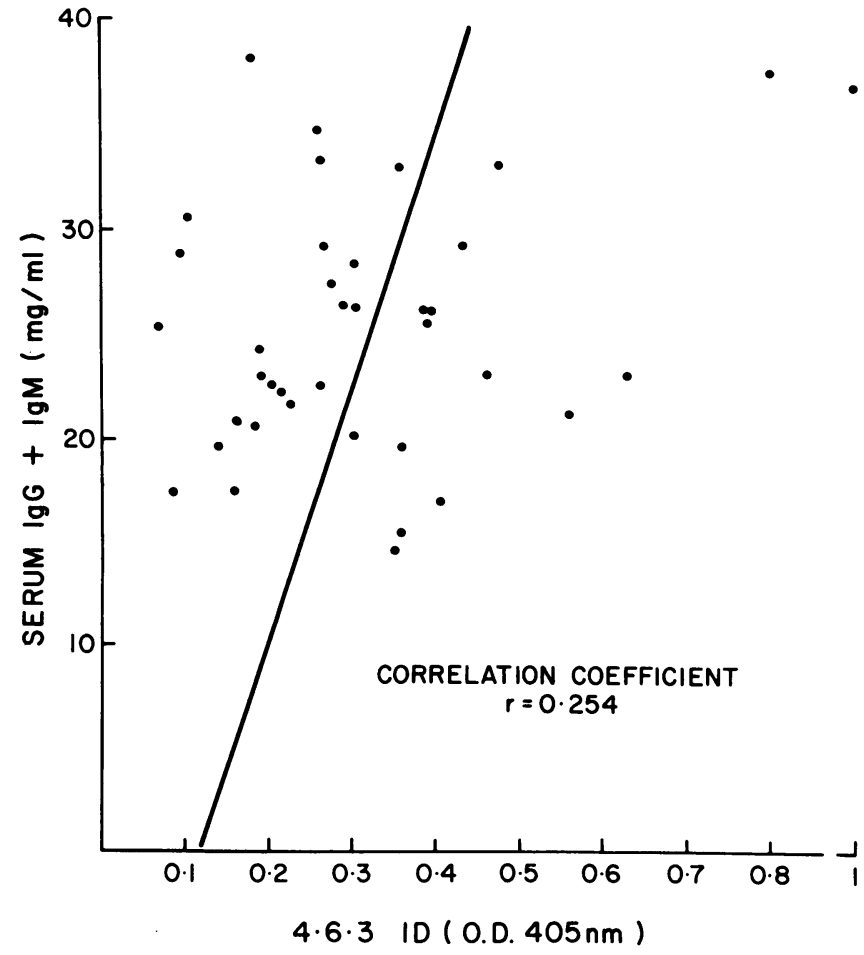

Figure 6. Correlation between serum IgG + IgM concentration and presence of 4.6.3 ID in SLE. (Data represent $\mathrm{OD}_{405} \mathrm{~nm}$ of SLE serum diluted $10^{-3}$ in ID 4.6 .3 assay.)

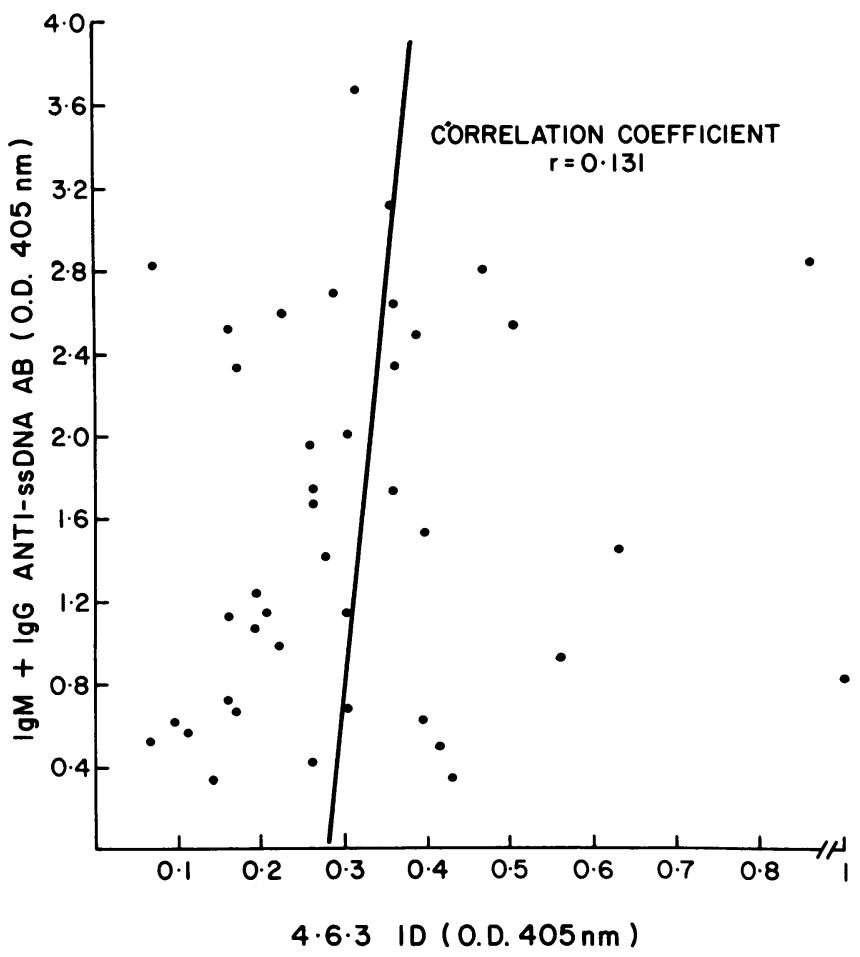

Figure 7. Correlation between IgG + IgM anti-ssDNA antibody and 4.6.3 ID in SLE sera. (Data represent $\mathrm{OD}_{405} \mathrm{~nm}$ of SLE serum diluted $10^{-3}$ in ID 4.6.3 assay.)

4.6.3) is shared with other hybridoma monoclonal DNA binding and non-DNA binding antibodies from different unrelated normals and with serum immunoglobulins from the majority of SLE patients. This cross-reactive idiotype(s) was identified

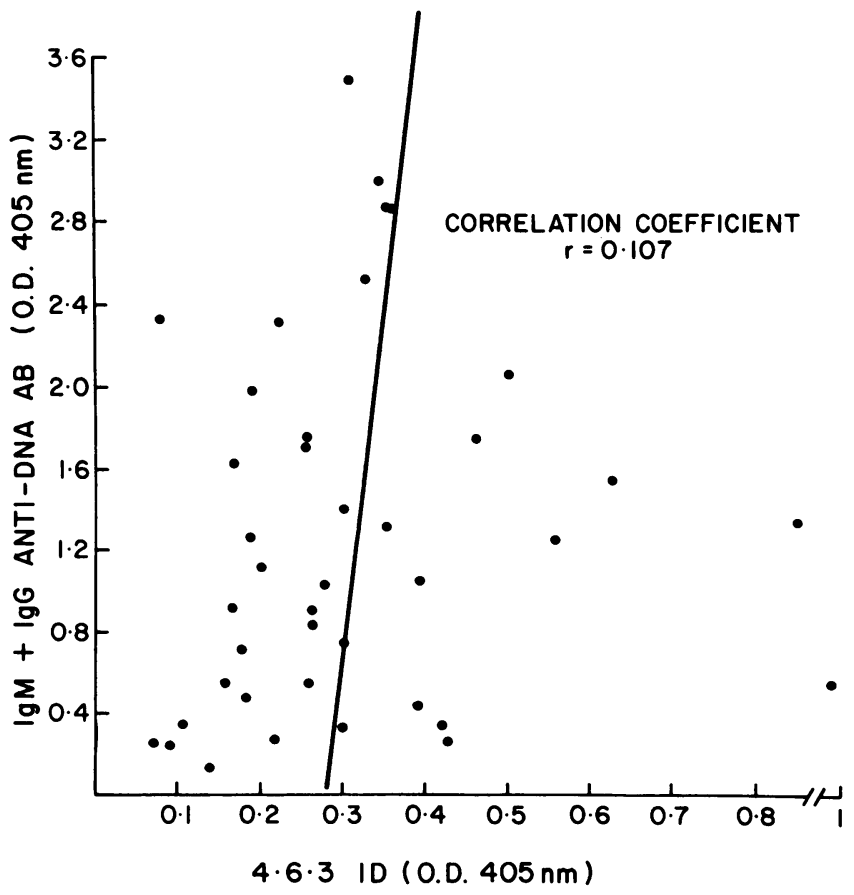

Figure 8. Correlation between IgG + IgM anti-DNA antibody and 4.6.3 ID in SLE sera. (Data represent $\mathrm{OD}_{405} \mathrm{~nm}$ of serum diluted $10^{-3}$ in 4.6 .3 ID assay.) 
with a rabbit antiserum made specific for the variable portion of IgM lambda anti-DNA antibody KIM 4.6.3 by absorption with normal human IgM and IgG. The resultant antiserum was therefore considered to represent an antibody to the 4.6.3 idiotype (anti-4.6.3 ID).

The specificity of anti-4.6.3 ID for KIM 4.6.3 anti-DNA antibody idiotype was indicated by $(a)$ the ability of anti-4.6.3 ID to bind to KIM 4.6 .3 antibody but not to normal human IgM, IgG or the GM 4672 hybridoma fusion partner supernatant, $(b)$ inhibition of anti-4.6.3 ID binding to KIM 4.6.3 by homologous affinity purified 4.6.3 IgM antibody and the 4.6.3 hybridoma supernatant but not by normal human IgM, IgG or GM 4672 supernatant, and (c) anti-4.6.3 ID inhibition of KIM 4.6.3 antibody binding to ssDNA.

The 4.6.3 ID was shown to be commonly expressed and was detected in $33 \%(10 / 30)$ of DNA and $32 \%$ (23/72) of nonDNA binding hybridoma monoclonal antibodies obtained from the tonsil fusions of five unrelated normal individuals (KIM, KIR, KEL, CAR, ROB). 4.6.3 ID expression shown here was determined by direct ELISA using anti-4.6.3 ID with the undiluted hybridoma $\mathrm{S} / \mathrm{N}$ sample which gave the highest IgM concentration achievable for a given culture. The concentrations of $\operatorname{IgM}$ in these $\mathrm{S} / \mathrm{N}$ studied varied from 0.45 $\mu \mathrm{g} / \mathrm{ml}$ to $8 \mu \mathrm{g} / \mathrm{ml}$. The 4.6.3 ID was detected among $\mathrm{S} / \mathrm{N}$ with the lowest, as well as the highest IgM concentration. This indicates that the level of IgM was not the limiting factor in idiotype detection.

Supernatants that were positive for 4.6.3 ID by the above direct ELISA assays were also positive by an inhibition assay. Thus the 4.6.3 ID positive supernatants inhibited the binding of KIM 4.6.3 ID to anti-4.6.3 ID. In contrast, 4.6.3 ID negative antibodies (as assessed by the direct ELISA assay) were not inhibitory. This indicates that there were no conformational differences in the 4.6.3 ID whether present in a fluid phase or bound on a solid support.

The monoclonal antibodies expressing 4.6.3 ID were predominantly IgM lambda although one monoclonal antibody 9.1, an $\operatorname{IgM}_{\kappa}$ showed limited ability to inhibit the 4.6.3 anti-4.6.3 antibody reaction. These data suggest an important contribution of the lambda light chain for the expression of ID 4.6.3. This suggestion is further strengthened by our recent observation on the ability of Burkitt's lymphoma cell line-BL2 (a lambda light chain non-heavy chain producer) and myeloma cell line-Hd (an IgA lambda producer) both of which express the same V lambda gene as KIM 4.6.3 to interfere with KIM 4.6.3-anti-4.6.3 reactivity (manuscript submitted). Among monoclonal DNA binding antibodies, 4.6.3 ID was found on polyspecific antibodies (3) which reacted with a variety of nucleic acid antigens and which also had weak binding to cardiolipin. Neither monospecific anti-DNA antibodies nor polyspecific antibodies with strong binding to cardiolipin, nor monospecific anti-cardiolipin antibodies (e.g., 13.1) (3) expressed the 4.6.3 ID.

The location of the idiotypic determinants recognized by anti-4.6.3 ID have not been determined with respect to a particular site on the light and/or heavy chain variable regions. Framework regions however seem most likely to be involved in the expression of such determinants since with three exceptions, binding interactions of the majority of 4.6.3 ID positive anti-DNA antibodies with ssDNA were not anti-4.6.3 ID inhibitable. The finding of similar frequencies of 4.6.3 ID on DNA+ and DNA- antibodies also argues against 4.6.3 ID being within the nucleic acid antigen reactive site. The latter finding invites speculation that perhaps anti-4.6.3 ID recognizes determinants which are derived from a common $V_{\mathrm{H}}$ and/or $V_{L}$ gene family or from a particular $J$ and/or $D$ segment. Relevant to this possibility is the finding of Margolies et al. (20) in the arsonate system of a major cross-reactive idiotype which was shown to be expressed by hapten-binding and nonbinding antibodies. Structural differences in $\mathrm{D} / \mathrm{JH}$ junction and $\mathrm{JH}$ segments were held responsible for arsonate reactivity, and sites outside the antigen binding regions in $V_{H}$ segments were implied to confer the idiotype specificity.

The 4.6.3 cross-reactive ID, although expressed by normal tonsil lymphoid cells in vitro, was either not expressed or infrequently expressed and at low levels in normal individuals in vivo. Only $24 \%$ of normal human serum immunoglobulins expressed this idiotype and the mean level was quite low $\left(0.05 \pm 0.04 \mathrm{OD}_{405 \mathrm{~nm}}\right)$. Amongst the normal sera lacking 4.6.3 ID was serum from the donor whose tonsil lymphoid cells were used to generate hybridomas and from which the 4.6.3 ID described here was originally derived. These findings suggest that the expression of this anti-DNA antibody cross-reactive idiotype may be suppressed in vivo in normal individuals. In contrast, this in vitro normal-derived anti-DNA antibody 4.6.3 ID was expressed on the serum immunoglobulins of $85-90 \%$ of unselected SLE patients and its mean level of $0.26 \pm 0.2 \mathrm{OD}_{405 \mathrm{~nm}}$ was significantly higher than the level of 4.6.3 ID in normal sera. The high frequency of 4.6.3 ID in SLE sera was not merely a reflection of the high serum immunoglobulin concentrations often seen in SLE since sera from patients with unexplained polyclonal hypergammaglobulinemia expressed 4.6.3 ID at the similar low frequency found in normal sera. Further, there was no correlation in SLE sera between IgM and IgG concentration and 4.6.3 ID concentration. Differences in 4.6.3 ID expression in normal and SLE sera suggest that preferential utilization of 4.6.3 ID encoding gene segment(s) or expansion of 4.6.3 ID bearing B cells is relevant to the SLE disease process. Since the 4.6.3 ID was also expressed very commonly and at levels similar to SLE among sera of patients with monoclonal IgM paraproteins, particularly IgM lambda with cold agglutinin activity (21) the B cells of these patients may have properties similar to those of SLE. In isolated cases, the level of 4.6.3 ID in SLE sera paralleled the clinical course of SLE but was often independent of serum levels of anti-DNA antibody (21). In randomly tested SLE sera, no correlation of 4.6.3 ID and IgM and/or IgG antibodies to ssDNA and/or DNA was found. This however does not exclude the possibility that some SLE serum anti-DNA antibodies bear 4.6.3 ID. Some serum 4.6.3 ID-positive anti-DNA antibodies may have escaped detection by anti-4.6.3 ID because of their association with antigen as immune complexes (22) or because such antibodies may be deposited in different tissue sites. These possibilities can be supported by recent reports describing the presence of an SLE major anti-DNA antibody cross-reactive idiotype designated $16 / 6$ in renal glomerulus and skin tissue lesions $(23,24)$ and by the inability to detect anti-DNA antibody reactivity on antibodies bearing cross-reactive idiotype by conventional assays (25). It is also possible that the 4.6.3 ID family may be expressed in SLE sera on other antibodies to different antigens such as Ro (SS-A); La (SS-B), or Sm/nRNP. This question is presently being actively pursued in our laboratory. Further, as noted above the 4.6.3 ID was frequently found in the serum of patients with mono- 
clonal IgM lambda macroglobulinaemia with cold agglutinin activity.

The common expression of 4.6.3 ID strongly suggests that this idiotype is encoded by a germ line Ig variable light and/or variable heavy gene ( $V_{\mathrm{L}}$ and/or $\mathrm{JL} ; V_{\mathrm{H}}$ and/or $\mathrm{D}$ and/or $\left.\mathrm{JH}\right)$. The same suggestion was put forward by other investigators (11, 15, 26-29) who studied genetic elements encoding SLE anti-DNA antibodies using antiidiotype probes raised against idiotypes on nucleic acid reactive lupus-derived antibodies. Our experimental reciprocal approach examining the abnormal expression of a normal-derived ID complements theirs and the findings among these groups are thus similar. For example the cross-reactive idiotype $\mathrm{H}-130$ expressed by antiDNA antibody from MRL/lpr/lpr autoimmune strain of mice was described by Andrzejewski et al. (27). In this strain of mice $\mathrm{H}-130$ was represented in about $50 \%$ of the serum immunoglobulins and less than half of the $\mathrm{H}-130$ positive Ig had antinucleic acid reactivity. Different strains of autoimmune mice shared H-130 ID (28). A correlation of this ID expression and the severity of the disease in MRL/lpr/lpr mice was noted. Furthermore, lipopolysaccharide (LPS) stimulated the production of anti-DNA antibodies bearing $\mathrm{H}-130$ in normal spleen lymphocyte cultures (15).

In man, a public idiotypic marker termed $16 / 6$ derived from an SLE monoclonal anti-DNA antibody was shared with monoclonal anti-DNA antibodies from different SLE patients (29) with serum immunoglobulins from more than half of the SLE patients with active disease, and with $4 \%$ of normal human sera (30). Some pathogenic relevance was assigned to 16/6 ID since its presence could be demonstrated in skin and the renal glomerulus from SLE patients $(23,24)$. Peripheral blood lymphocytes from normal individuals produced Ig, which expressed the 16/6 ID in vitro after stimulation with pokeweed mitogen (31), with bacteria (32), or with $\alpha$-interferon (33). Some of the 16/6 ID-positive antibodies in the cultures with $\alpha$-interferon were DNA reactive. We have also shown that the immunoglobulins from normal peripheral blood lymphocytes in short-term pokeweed mitogen stimulated cultures expressed ID 4.6.3 but did not bind DNA (21). Another public idiotype, 3I, was described for human antiDNA antibodies (11). It was identified by a mouse monoclonal antibody obtained from spleen cells of a mouse immunized with affinity-purified human IgG SLE serum anti-DNA antibodies. This 3I idiotypic marker was expressed at high levels in $85 \%$ of the sera from SLE patients. The sera from unaffected SLE relatives also contained antibodies with 3I ID but without DNA binding properties. The relationship among these different idiotypes is under study.

A uniform picture emerges from these findings. The antiDNA antibodies of SLE and normal individuals are idiotypically related to one another and are also idiotypically related to non-DNA binding antibodies. The molecular analyses which have already been initiated support the idea that these antinucleic acid autoantibodies are encoded by germ line genes (34, 35). In our laboratory, we have recently completed cloning and nucleotide sequence analyses of $V_{\mathrm{H}}$ and $V_{\mathrm{L}}$ genes encoding KIM 4.6.3 anti-DNA antibody and found that 4.6.3 ID is also of germ line gene origin (manuscript in preparation). Experiments are underway to precisely determine whether the variable light or heavy chain genes (or their segments) correlate with 4.6.3 ID expression amongst the various DNA and nonDNA antibodies studied here.

\section{Acknowledgments}

The authors wish to thank Mrs. Marlyn C. French for typing the manuscript.

Supported by a grant from the Arthritis Society, Toronto, Canada.

\section{References}

1. Cairns, E., J. St. Germain, and D. A. Bell. 1985. The in vitro production of anti-DNA antibody by cultured peripheral blood or tonsillar lymphoid cells from normal donors and SLE patients. $J$. Immunol. 135:3839-3844.

2. Hoch, S., P. H. Schur, and J. Schwaber. 1983. Frequency of anti-DNA antibody producing cells from normals and patients with systemic lupus erythematosus. Clin. Immunol. Immunopathol. 27:2837.

3. Cairns, E., J. Block, and D. A. Bell. 1984. Anti-DNA autoantibody-producing hybridomas of normal human lymphoid cell origin. $J$. Clin. Invest. 74:880-887.

4. Rauch, J., H. Massicotte, and H. Tannenbaum. 1985. Hybridoma anti-DNA autoantibodies from patients with rheumatoid arthritis and systemic lupus erythematosus demonstrate similar nucleic acid binding characteristics. J. Immunol. 134:180-186.

5. Hoch, S., and J. Schwaber. 1986. Specificity analysis of human anti-DNA antibodies. J. Immunol. 136:892-897.

6. Pancer, L. B., D. A. Bell, and S. K. Singhal. 1980. Induction of anti-ssDNA antibodies in normal and preautoimmune mice in vivo. $J$. Immunol. 124:939-946.

7. Fish, F., and M. Ziff. 1982. The in vitro and in vivo induction of anti-double stranded DNA antibodies in normal and autoimmune mice. J. Immunol. 128:409-414.

8. Shoenfeld, Y., J. Rauch, H. Massicotte, S. K. Datta, J. AndreSchwartz, B. D. Stollar, and R. S. Schwartz. 1983. Polyspecificity of monoclonal lupus autoantibodies produced by human-human hybridomas. N. Engl. J. Med. 308:414-420.

9. Andre-Schwartz, J., S. K. Datta, Y. Shoenfeld, D. A. Isenberg, B. D. Stollar, and R. S. Schwartz. 1984. Binding of cytoskeletal proteins by monoclonal anti-DNA lupus autoantibodies. Clin. Immunol. Immunopathol. 31:261-271.

10. Cairns, E., R. Komar, and D. A. Bell. 1986. Cytoskeletal binding of monoclonal anti-DNA antibodies derived from tonsillar lymphoid cells of a normal individual. Arthritis Rheum. 29(11):13511359.

11. Solomon, G., J. Schiffenbauer, H. D. Keiser, and B. Diamond. 1983. Use of monoclonal antibodies to identify shared idiotypes on human antibodies to native DNA from patients with systemic lupus erythematosus. Proc. Natl. Acad. Sci. USA. 80:850-854.

12. Shoenfeld, Y., D. A. Isenberg, J. Rauch, M. P. Madaio, B. D. Stollar, and R. S. Schwartz. 1983. Idiotypic crossreactions of monoclonal human lupus autoantibodies. J. Exp. Med. 158:718-730.

13. Rauch, J., E. Murphy, J. B. Roth, B. D. Stollar, and R. S. Schwartz. 1982. A high frequency idiotypic marker of anti-DNA autoantibodies in MRL/lpr/lpr mice. J. Immunol. 129:236-241.

14. Mayus, J. L., and D. S. Pisetsky. 1985. Expression of a highly conserved anti-DNA idiotype in normal and autoimmune mice. Clin. Immunol. Immunopathol. 34:366-378.

15. Datta, S. K., B. D. Stollar, and R. B. Schwartz. 1983. Normal mice express idiotypes of lupus mice. Proc. Natl. Acad. Sci. USA. 80:2723-2727.

16. Halpern, R., A. Davidson, A. Lazo, G. Solomon, R. Lahita, and B. Diamond. 1985. Familial systemic lupus erythematosus. Presence of a crossreactive idiotype in healthy family members. J. Clin. Invest. 76:731-736.

17. Atkinson, P. M., G. W. Lapman, B. C. Furie, Y. Naparstek, and R. S. Schwartz. 1985. Homology of the $\mathrm{NH}_{2}$-terminal amino acid sequences of the heavy and light chains of human monoclonal lupus 
autoantibodies containing the dominant $16 / 6$ idiotype. J. Clin. Invest. 75:1138-1143.

18. Kofler, R., D. J. Noonan, D. E. Levy, M. C. Wilson, N. P. H Moller, F. J. Dixon, and A. N. Theofilopoulos. 1985. Genetic elements used for a murine lupus anti-DNA autoantibody are closely related to those for antibodies to exogenous antigens. J. Exp. Med. 161:805-815.

19. Pancer, L. B., M. F. Millazo, V. L. Morris, S. K. Singhal, and D. A. Bell. 1981. Immunogenicity and characterization of supernatant DNA released by murine spleen cells. J. Immunol. 127:98-104.

20. Margolies, M. N., E. C. Juszczak, R. Near, A. Marshak-Rothstein, T. L. Rothstein, V. L. Sato, M. Siekevitz, J. A. Smith, L. J. Wysocki, and M. L. Gefter. 1983. Structural correlates of idiotypy in the arsonate system. Ann. NY Acad. Sci. 418:48-64.

21. Bell, D. A., E. Cairns, K. Cikalo, V. Ly, J. Block, and W. Pruzanski. 1987. Antinucleic acid autoantibody responses of normal human origin; Antigen specificity and idiotypic characteristics compared to patients with systemic lupus erythematosus and patients with monoclonal IgM. J. Rheumatol. 14(S13):127-131.

22. Fish, F., and M. Ziff. 1982. Hidden anti-double stranded DNA antibodies in autoimmune mice. Clin. Exp. Immunol. 49:587-597.

23. Isenberg, D. A., and C. Collins. 1985. Detection of crossreactive anti-DNA antibody idiotypes on renal tissue-bound immunoglobulins from lupus patients. J. Clin. Invest. 76:287-294.

24. Isenberg, D. A., C. Dudeney, F. Wejnaruska, B. S. Bhogal, J. Rauch, A. Schattner, Y. Naparstek, and D. Duggan. 1985. Detection of crossreactive anti-DNA antibody idiotypes on tissue-bound immunoglobulins from skin biopsies of lupus patients. J. Immunol. 135:261-264.

25. Halpern, R., J. Schiffenbauer, G. Solomon, and B. Diamond. 1984. Detection of masked anti-DNA antibodies in lupus sera by a monoclonal antiidiotype. J. Immunol. 133:1852-1856.

26. Tron, G., C. LeGuern, P. A. Cazenave, and J. F. Bach. 1982. Intrastrain recurrent idiotypes among anti-DNA antibodies of (NZB $\times \mathrm{NZW}) \mathrm{F}_{1}$ hybrid mice. Eur. J. Immunol. 12:761-766.
27. Andrzejewski, CH., Jr., J. Rauch, E. Lafer, B. D. Stollar, and R. S. Schwartz. 1981. Antigen binding diversity and idiotypic crossreactions among hybridoma autoantibodies to DNA. J. Immunol. 126:226-231.

28. Rauch, J., E. Murphy, J. B. Roths, B. D. Stollar, and R. S. Schwartz. 1982. A high frequency idiotypic marker of anti-DNA autoantibodies in MRL/lpr/lpr mice. J. Immunol. 129:236-241.

29. Shoenfeld, Y., D. A. Isenberg, J. Rauch, M. Madaio, B. D. Stollar, and R. S. Schwartz. 1983. Idiotypic crossreactions of monoclonal human lupus autoantibodies. J. Exp. Med. 158:718-730.

30. Isenberg, D. A., Y. Shoenfeld, M. J. Madaio, J. Rauch, M. Reichlin, B. D. Stollar, and R. S. Schwartz. 1984. Anti-DNA antibody idiotypes in systemic lupus erythematosus. Lancet. ii:417-422.

31. Datta, S. K., Y. Naparstek, and R. S. Schwartz. 1986. In vitro production of an anti-DNA idiotype by lymphocytes of normal subjects and patients with systemic lupus erythematosus. Clin. Immunol. Immunopathol. 38:302-318.

32. El-Roiey, A., W. L. Gross, J. Luedemann, D. A. Isenberg, and Y. Shoenfeld. 1986. Preferential secretion of a common anti-DNA idiotype (16/6 ID) and anti-polynucleotide antibodies by normal mononuclear cells following stimulation with Klebsiella pneumoniae. Immunol. Lett. 12:313-319.

33. Schattner, A., D. Duggan, Y. Naparstek, and R. S. Schwartz. 1986. Effects of interferon- $\alpha$ on the expression of a lupus idiotype in normal humans. Clin. Immunol. Immunopathol. 38:327-336.

34. Naparstek, Y., J. Andre-Schwartz, T. Manser, L. J. Wysocki, L. Breitman, B. D. Stollar, M. Gefter, and R. S. Schwartz. 1986. A single germline $\mathrm{V}_{\mathrm{H}}$ gene segment of normal $\mathrm{A} / \mathrm{J}$ mice encodes autoantibodies characteristic of systemic lupus erythematosus. J. Exp. Med. 164:614626.

35. Dersimonian, H., R. S. Schwartz, K. J. Barrett, and B. D. Stollar. 1987. Relationship of human variable region heavy chain germ-line genes to genes encoding anti-DNA autoantibodies. J. Immunol. 139:2496-2501. 